\title{
Papers
}

\section{Randomised controlled trial of efficacy of teaching patients with bipolar disorder to identify early symptoms of relapse and obtain treatment}

\author{
Alison Perry, Nicholas Tarrier, Richard Morriss, Eilis McCarthy, Kate Limb
}

\begin{abstract}
Objective To determine the efficacy of teaching patients with bipolar disorder (manic-depressive psychosis) to identify early symptoms of relapse and seek prompt treatment from health services.

Design Single blind randomised controlled trial with matching on four baseline variables using a minimisation algorithm.

Setting Mental health services in four NHS trusts (one teaching, three non-teaching).

Subjects 69 patients with bipolar disorder who had had a relapse in the previous 12 months.

Interventions Seven to 12 individual treatment sessions from a research psychologist plus routine care or routine care alone.

Main outcome measures Time to first manic or depressive relapse, number of manic or depressive relapses, and social functioning examined by standardised interviews every six months for 18 months.

Results 25th centile time to first manic relapse in experimental group was 65 weeks compared with 17 weeks in the control group. Event curves of time to first manic relapse significantly differed between experimental and control groups (log rank 7.04, $\mathrm{df}=1, \mathrm{P}=0.008$ ), with significant reductions in the number of manic relapses over 18 months (median difference $30 \%$ (95\% confidence interval $8 \%$ to $52 \%$ ), $\mathrm{P}=0.013)$. The experimental treatment had no effect on time to first relapse or number of relapses with depression, but it significantly improved overall social functioning (mean difference 2.0 (0.7 to 3.2 ),

$\mathrm{P}=0.003)$ and employment (mean difference 0.7 (0.1 to 1.3 ), $\mathrm{P}=0.030$ ) by 18 months.

Conclusion Teaching patients to recognise early symptoms of manic relapse and seek early treatment is associated with important clinical improvements in time to first manic relapse, social functioning, and employment.
\end{abstract}

\section{Introduction}

Bipolar disorder (manic-depressive psychosis) is a common serious mental illness characterised by two types of relapse, mania (elation with disinhibited, overactive behaviour) and depression. ${ }^{1}$ Relapse rates of
$50 \%$ at one year ${ }^{2-6}$ and $70 \%$ at five years ${ }^{4}{ }^{7}$ after a manic episode suggest the need for more effective therapeutic strategies to prevent relapses in bipolar disorder. Three retrospective studies ${ }^{8-10}$ and two prospective studies ${ }^{11} 12$ showed identifiable and consistent prodromal symptoms of manic or depressive relapse at two to four weeks before full relapse in most patients with bipolar disorder. These prodromal symptoms are idiosyncratic to both the patient and to the type of relapse (mania or depression). We conducted a randomised controlled trial of the efficacy of recognising prodromal symptoms of manic or depressive relapse followed by early conventional treatment.

\section{Patients and methods}

Patients who had a clinical diagnosis of manicdepressive psychosis (bipolar disorder) and who might be eligible for the study were systematically identified from computerised patient records of hospital admissions to three NHS trusts in the north west of England. Patients were approached if their consultant psychiatrist and keyworker agreed. In addition, patients were referred by consultant psychiatrists and mental health workers in these trusts, with two patients being referred by a consultant psychiatrist in a neighbouring trust. Inclusion criteria were a lifetime diagnosis of bipolar disorder ${ }^{1}$ elicited by a trained research assistant (EMcC, KL, AP) using a standardised psychiatric interview $^{13}$; two or more relapses, ${ }^{1}$ one in the previous 12 months; and age 18 to 75 years. Exclusion criteria were an inability to read or write in English; drug or alcohol misuse or dependence ${ }^{1}$ as a primary problem; and an organic cerebral cause for bipolar disorder-for example, multiple sclerosis or stroke. The study was approved by a medical ethics committee in each NHS trust. Each patient gave written informed consent to the trial.

After assessment at baseline each patient was sequentially entered into the study and randomly allocated to either the experimental or control group using the principle of minimisation. ${ }^{14}$ Allocation was based on four stratification factors: age (18 to 40 years $v 41$ to 75 years),${ }^{15}$ sex, ${ }^{15}$ prescription of lithium, ${ }^{16}$ and presence or absence of a carer (minimum of 10 hours of contact with patient). ${ }^{17} \mathrm{~A}$ research assistant (AP) typed the relevant details of each patient suitable for
Department of Clinical Psychology, University of Manchester, Withington Hospital, Manchester M20 8LR

Alison Perry, research assistant Nicholas Tarrier, professor Eilis McCarthy, research assistant Kate Limb, research assistant Department of Community Psychiatry, University of Manchester, and Guild NHS Trust, Royal Preston Hospital, Preston PR2 9HT

Richard Morriss, senior lecturer

Correspondence to: Dr Morriss

BMJ 1999;318:149-53 
randomisation into a dedicated computer program, which computed the group to which the patient should be allocated. This information was displayed on the computer monitor and recorded. The study was single blind: the study raters (EMcC, KL) were denied access to the randomisation and treatment until the study was completed but therapists and patients knew the treatment allocation immediately after randomisation.

Fifty patients were required in each treatment group to have a power of $80 \%$ in detecting a reduction in overall (mania and depression) relapse rate at 12 months from $50 \%$ in the control group ${ }^{2-6}$ to $25 \%$ in the experimental group at a significance level of $5 \%$ in two tailed tests.

\section{Treatment}

The experimental treatment ${ }^{18}$ was a collaboration between the patient and a research psychologist with little previous clinical experience (AP). Treatment occurred in two stages: training the patient to identify prodromal symptoms (prodromes) of manic or depressive relapse separately and producing and rehearsing an action plan once prodromes had been recognised by the patient. A history was obtained of life circumstances and symptoms leading to previous manic and depressive relapses. The nature and timing of the prodromal symptoms were elicited by using a standard checklist ${ }^{9}$ and a card sorting exercise ${ }^{19}$ in which the patient placed prodromal symptoms written on cards in temporal order of occurrence. Diaries were kept to distinguish symptoms associated with normal mood variation from prodromes. Three symptoms or life situations which reliably occur early in the manic or depressive prodrome constituted a warning stage for the patient to increase monitoring from weekly to daily. Three further symptoms or life situations occurring later in the prodrome constituted an action stage to seek help from a health professional of the patient's choice.

The therapist and patient identified three health professionals for seeking early treatment, one of whom would be available at all times-for example, a general practitioner or a doctor in an accident and emergency department. The full relapse plan of warning and action stage prodromal symptoms for manic and depressive relapse with the plan for seeking treatment was recorded on a card in laminated plastic, which was carried by the patient. The therapist then informed the health staff who would be called on to treat the patient (always informing consultant psychiatrist, key worker, and general practitioner). We compared the combination of experimental treatment and routine treatment with routine treatment alone. Routine care delivered by psychiatrists and key workers consisted of drug treatment, monitoring of mood and adherence to treatment, support, education about bipolar disorder, and if necessary inpatient care.

\section{Assessment}

All patients in both groups were assessed with standardised psychiatric ${ }^{13}$ and social functioning ${ }^{20}$ interviews by a trained research assistant (EMcC, KL) at baseline and at six, 12, and 18 months after randomisation. A relapse was defined as a minimum of five days of symptoms of mania, hypomania, mixed affective disorder, or major depression according to the standardised symptom criteria (the two week duration criterion for major depression was ignored). The social functioning interview examined behaviour on a four point scale in eight areas of social activity (household management, employment, management of money, child care, intimate relationship with spouse or partner, non-intimate relationship with another adult, social presentation to other people, and coping with an emergency). ${ }^{20}$ On each scale, 0 indicated fair to good performance, 1 a serious problem on occasions but sometimes managing quite well, 2 serious problems most of the time, and 3 inability to carry out the social activity. Serious problems on the employment scale included timekeeping, unauthorised absence, relations with peers and supervisors, and quantity or quality of output. An overall score of social functioning was obtained by summing the scores of the eight areas.

Each month the research assistant (EMcC, KL) contacted each patient's consultant psychiatrist and key worker (community psychiatric nurse, social worker, community occupational therapist) to identify contacts between these health professionals and the patient and determine whether he or she had had a relapse. If there was evidence of relapse, the patient was interviewed by the research assistant using the standardised psychiatric interview before the next six month assessment to date the relapse accurately. During each period of six months the research assistant checked the patient's notes recording drug treatment, all contacts with mental health services, and admissions to hospital. Drug treatment was recorded in $\mathrm{mg}$ equivalents of imipramine (antidepressants), chlorpromazine (neuroleptics), diazepam (benzodiazepines), procyclidine (anticholinergics), lithium, carbamazepine, and valproate. ${ }^{21}$ The newest serum concentration of lithium, carbamazepine, and valproate was recorded from the patient's notes and compared with the hospital laboratory's reference range as a check on patients' adherence to their drug regimen to stabilise mood.

Manic and depressive relapses were treated as independent outcomes because both the experimental and control treatments differed qualitatively for mania and depression. Time to relapse was plotted on event curves, which were analysed with the log rank test. The highly skewed data on relapse and treatment were analysed using $\chi^{2}$ tests, Mann-Whitney U tests, and median differences with $95 \%$ confidence intervals. Data on relapse were complete except for one patient who died of ischaemic heart disease in the experimental group before the first assessment at six months. Scores on the patient's previous assessment were substituted when data on the social function scale were missing. Changes in the data from the social functioning interview were almost normally distributed. They were examined using mean differences with $95 \%$ confidence intervals and factorial analysis of variance with the experimental treatment as the between subjects factor.

\section{Results}

Figure 1 shows the flow of subjects recruited to the study. The study was carried out between March 1994 and April 1997. Table 1 shows that demographic data 


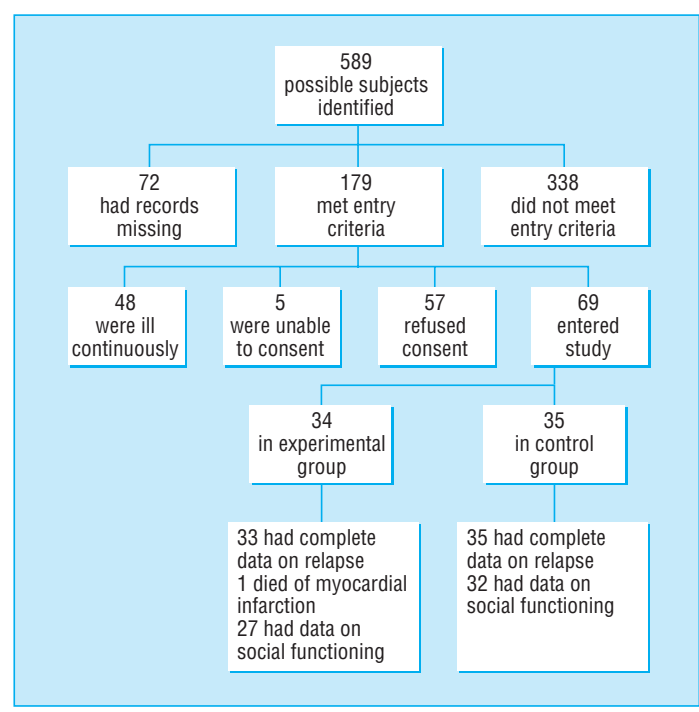

Fig 1 Flow chart of subjects recruited to study

Table 1 Demographic and clinical characteristics at baseline. Values are numbers (percentages) of patients unless stated otherwise

\begin{tabular}{lcc} 
Variable & $\begin{array}{c}\text { Experimental group } \\
(\mathbf{n}=34)\end{array}$ & $\begin{array}{c}\text { Control } \\
\text { group }(\mathbf{n}=35)\end{array}$ \\
\hline Mean (SD) age (years) & $44(13)$ & $45(11)$ \\
\hline Women & $23(68)$ & $24(69)$ \\
\hline Prescribed lithium & $23(68)$ & $25(71)$ \\
\hline Contact with carer for $\geqslant 10 \mathrm{~h} /$ week & $23(68)$ & $21(60)$ \\
\hline Married or cohabiting & $22(65)$ & $21(60)$ \\
\hline White ethnic origin & $30(88)$ & $33(94)$ \\
\hline Education over 16 years old & $16(47)$ & $13(37)$ \\
\hline Employed & $9(26)$ & $6(17)$ \\
\hline Median duration of illness (range) (years) & $11(2-41)$ & $12(2-34)$ \\
\hline Type of bipolar illness: & $30(88)$ & $33(94)$ \\
\hline I $^{*}$ & $4(12)$ & $2(6)$ \\
\hline II† & $6(2-25)$ & $5(2-17)$ \\
\hline Median No of bipolar episodes (range) & $5(1-21)$ & $5(0-19)$ \\
\hline Median No of psychiatric admissions (range) & $25(16)$ & $25(18)$ \\
\hline Mean (SD) No of weeks since last relapse & $3(9)$ & $4(11)$ \\
\hline Personality disorder & $7(21)$ & $6(17)$ \\
\hline Other psychiatric disorder $\ddagger$ & $30(88)$ & $31(89)$ \\
\hline Prescribed mood stabilising drugs
\end{tabular}

${ }^{*}$ Recurrent mania requiring admission together with major depression.

†Recurrent major depression with occasional hypomania not requiring admission $\ddagger$ bssessive compulsive disorder $(n=4)$, social phobia $(n=3)$, generalised anxiety disorder $(n=2)$, anxiety disorder not otherwise specified $(n=2)$, simple phobia $(n=2)$.

and baseline variables were not significantly different between the experimental and control groups. There were no clinically important age and sex differences between study subjects and refusers (mean age 43 (SD $15)$ years, $39 / 57(68 \%)$ women). Percentage agreement (interrater reliability) between a psychiatrist (RM) and the three research assistants using the standardised psychiatric interview ${ }^{13}$ to rate the presence or absence of 70 current or past psychiatric episodes was 95\% (kappas 0.84, 0.93, and 0.94).

The median number of experimental sessions lasting one hour each was nine (range 0-12). The completed experimental treatment was between seven and 12 sessions of one hour each (median 9, range $0-12$ ). The variation occurred because patients who had only manic relapses had fewer sessions, patients who had relapses during treatment had extra revision sessions, and some patients took longer to identify prodromal symptoms. Seven patients were allocated to the experimental treatment but did not complete it, five because of time commitments (two had no sessions, two one session, and one three sessions), one because she became pregnant and stopped attending (five sessions), and one because she became depressed and did not find the sessions helpful (six sessions).

Figure 2 shows that the 25th centile time to first manic relapse was 65 weeks in the experimental group and 17 weeks in the control group. In contrast, figure 3 shows that the 25th centile time to first depressive relapse was 21 weeks in the experimental group and 26 weeks in the control group. The event curves for the experimental and control groups were significantly different for time to first manic relapse (log rank 7.04, $\mathrm{df}=1, \mathrm{P}=0.008$ ) but not for time to first depressive relapse $(\log$ rank $1.65, \mathrm{df}=1, \mathrm{P}=0.19)$.

Table 2 shows significant reductions in the total number of manic relapses between baseline and each six month period up to 18 months in the experimental group compared with the control group but no significant differences in the length of each manic relapse if it occurred. There were no significant changes in the number or length of depressive relapses. In 18 months $3(9 \%)$ patients in the experimental group and $2(6 \%)$

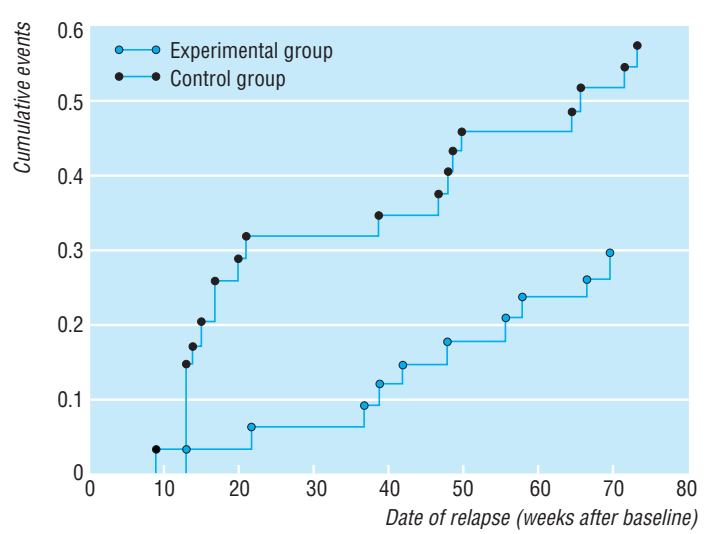

Fig 2 Event plot of time to first manic relapse in experimental and control groups

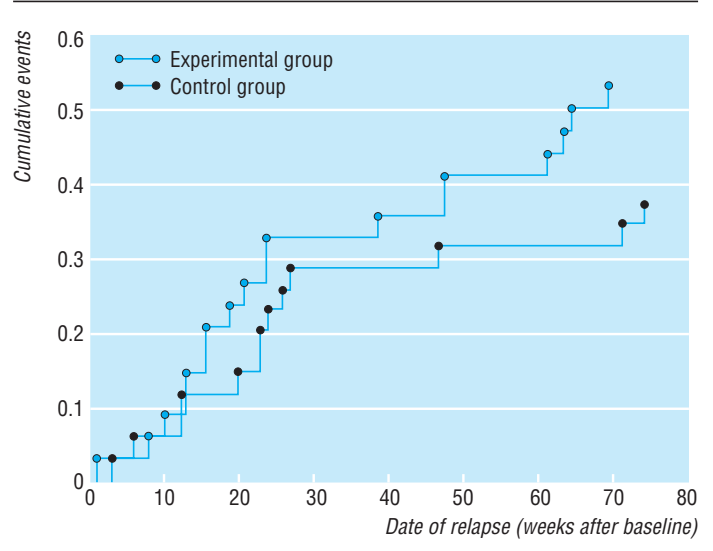

Fig 3 Event plot of time to first depressive relapse in experimental and control groups 
Table 2 Intention to treat analysis of relapse and treatment in experimental and control groups

\begin{tabular}{|c|c|c|c|c|c|c|c|c|}
\hline \multirow[b]{2}{*}{ Outcome measure (unit) } & \multicolumn{2}{|c|}{$\begin{array}{l}\text { No (\%) with relapse or } \\
\text { who received treatment }\end{array}$} & \multirow[b]{2}{*}{$\begin{array}{l}\text { Median difference } \\
\quad(95 \% \mathrm{Cl})\end{array}$} & \multirow[b]{2}{*}{$P$ value $†$} & \multicolumn{2}{|c|}{$\begin{array}{l}\text { Median (range) length of relapse } \\
\text { or treatment (days) }\end{array}$} & \multirow[b]{2}{*}{$\begin{array}{c}\text { Median difference } \\
\quad(95 \% \mathrm{Cl})\end{array}$} & \multirow[b]{2}{*}{$P$ value } \\
\hline & $\begin{array}{l}\text { Experimental } \\
(\mathrm{n}=33)^{\star}\end{array}$ & $\begin{array}{l}\text { Control } \\
(\mathrm{n}=35)\end{array}$ & & & Experimental & Control & & \\
\hline \multicolumn{9}{|l|}{ Baseline to 6 months } \\
\hline Mania (No of days) & $2(6)$ & $11(31)$ & $-25(-43$ to -8$)$ & 0.008 & $15(10-18)$ & $39(7-76)$ & Not computable & 0.28 \\
\hline Depression (No of days) & $11(33)$ & $9(26)$ & $8(-14$ to 29$)$ & 0.49 & $66(8-124)$ & $18(10-82)$ & $21(-5$ to 77$)$ & 0.17 \\
\hline \multicolumn{9}{|l|}{ Baseline to 12 months } \\
\hline Mania (No of days) & $6(18)$ & $16(46)$ & $-28(-49$ to -6$)$ & 0.016 & $15(10-56)$ & $45(7-106)$ & -19 (-61 to 3$)$ & 0.14 \\
\hline Depression (No of days) & $16(48)$ & $11(31)$ & $11(-12$ to 34$)$ & 0.35 & $48(7-233)$ & $25(10-187)$ & $12(-11$ to 71$)$ & 0.081 \\
\hline \multicolumn{9}{|l|}{ Baseline to 18 months } \\
\hline Mania (No of days) & $9(27)$ & $20(57)$ & $-30(-52$ to -8$)$ & 0.013 & $21(10-137)$ & $36(5-133)$ & $-11(-40$ to 20$)$ & 0.54 \\
\hline Depression (No of days) & $18(55)$ & $13(37)$ & $17(-6$ to 41$)$ & 0.15 & $48(7-238)$ & $61(10-187)$ & $2(-42$ to 46$)$ & 0.92 \\
\hline Admission (No of days) & $12(36)$ & $15(43)$ & $-6(-30$ to 17$)$ & 0.16 & $49(2-137)$ & $49(5-117)$ & $3(-30$ to 40$)$ & 0.77 \\
\hline Psychiatric outpatient visits (No) & $32(97)$ & $35(100)$ & $-3(-9$ to 28$)$ & 0.49 & $9(4-88)$ & $8(2-33)$ & $1(-1$ to 3$)$ & 0.31 \\
\hline Community contacts (No)§ & $16(48)$ & $18(51)$ & $3(-21$ to 27$)$ & 0.72 & $41(3-116)$ & $28(1-83)$ & $12(-10$ to 37$)$ & 0.28 \\
\hline Prescribed lithium (mg/day) & $24(73)$ & $26(74)$ & $-2(-23$ to 19$)$ & 0.88 & $800(93-1600)$ & $800(34-1336)$ & $0(-200$ to 191) & 0.92 \\
\hline Antidepressants (mg/day)ף & $17(52)$ & $14(40)$ & $12(-12$ to 35$)$ & 0.34 & $168(34-332)$ & $88(4-303)$ & $73(16$ to 131$)$ & 0.024 \\
\hline$\overline{\text { Neuroleptics }(\mathrm{mg} / \text { day })^{\star *}}$ & $25(76)$ & $24(69)$ & $7(-14$ to 28$)$ & 0.69 & $113(3-591)$ & $153(9-668)$ & $-37(-116$ to 28$)$ & 0.86 \\
\hline
\end{tabular}

${ }^{*}$ One patient died of ischaemic heart disease in first six months. $\dagger \chi^{2}$ test. $\ddagger$ Mann-Whitney $U$ test. §Community psychiatric nurses, mental health social workers, occupational therapists. Img equivalents of imipramine per day. ${ }^{\star *} \mathrm{mg}$ equivalents of chlorpromazine per day.

in the control group had a relapse of mixed affective disorder.

Table 2 also shows that there were few differences in other outcome measures between the experimental and control groups over the 18 months. The experimental group received significantly higher dosages of antidepressants than the control group. There was negligible use of benzodiazepines, valproate, anticholinergic drugs, electroconvulsive therapy, and day hospitals in both groups. Compliance with taking mood stabilising drugs as measured by the latest recorded blood concentration did not significantly differ between the two groups (data not shown).

Table 3 shows that there were significant improvements in overall social functioning and employment ${ }^{20}$ in the experimental group compared with the control group 18 months after the baseline assessment.

\section{Discussion}

The experimental treatment was effective in reducing manic but not depressive relapses because manic prodromes are more distinct ${ }^{11}$ and longer than depressive prodromes $^{89}$ and acute mania can be treated more quickly and effectively than acute depression. ${ }^{22}$ An

Table 3 Intention to treat analysis of social functioning and employment

\begin{tabular}{|c|c|c|c|}
\hline Mean (SD) score & $\begin{array}{l}\text { Experimental group } \\
\qquad(\mathrm{n}=34)\end{array}$ & $\begin{array}{c}\text { Control group } \\
(\mathrm{n}=35)\end{array}$ & $\begin{array}{l}\text { Mean difference } \\
(95 \% \mathrm{Cl})\end{array}$ \\
\hline \multicolumn{4}{|l|}{ Social function* } \\
\hline Total at baseline & $3.74(2.62)$ & $3.14(3.03)$ & - \\
\hline \multicolumn{4}{|l|}{ Change at: } \\
\hline 6 months & $-0.23(2.60)$ & $0.20(2.43)$ & $0.44(-0.78$ to 1.65$)$ \\
\hline 12 months & $-0.47(2.67)$ & $0.77(2.90)$ & $1.24(-0.10$ to 2.58$)$ \\
\hline 18 months & $-1.03(2.55)$ & $0.94(2.68)$ & 1.97 (0.71 to 3.23$)$ \\
\hline \multicolumn{4}{|l|}{ Employment† } \\
\hline Total at baseline & $1.68(1.45)$ & $1.51(1.48)$ & - \\
\hline \multicolumn{4}{|l|}{ Change at: } \\
\hline 6 months & $-0.24(1.16)$ & $0.09(1.22)$ & $0.32(-0.25$ to 0.89$)$ \\
\hline 12 months & $-0.44(1.08)$ & $0.17(1.65)$ & $0.61(-0.06$ to 1.29$)$ \\
\hline 18 months & $-0.59(1.13)$ & $0.11(1.47)$ & $0.70(0.07$ to 1.33$)$ \\
\hline
\end{tabular}

increased awareness of depressive symptoms without the skills to cope with them may be wasteful since the experimental group received significantly higher doses of antidepressants. The intervention probably improved social function by increasing confidence in coping with relapse, which confirms the results from cross sectional studies. ${ }^{10}$ Cumulative improvements in social function imply a specific treatment effect rather than the non-specific effects of support from an empathic therapist.

The sample is representative of patients with bipolar disorder who are in contact with hospital services in terms of the ratio of women to men $(2: 1)^{1523}$ and of rates of manic to depressive relapse (about equal). ${ }^{2} \mathrm{We}$ may, however, have missed some brief relapses with our method of follow up assessment. Non-participation because of the length of the intervention resulted in lower recruitment than our power calculation (which assumed modest effects from treatment compared with

Key messages

- Relapse rates in bipolar disorder are high despite modern drug treatment

- Early prodromal symptoms are idiosyncratic to the patient and consistently develop in the weeks before manic or depressive relapse

- This study found that teaching patients to recognise manic prodromes and seek early treatment significantly increased time to the next manic relapse and reduced the number of relapses

- Teaching patients to recognise depressive prodromes and seek early antidepressant treatment did not significantly affect depressive relapses and increased the use of antidepressants

- Teaching patients to recognise prodromes and seek early treatment improved social function and performance in employment 
analogous results from research into schizophrenia ${ }^{24}$ ) but all participants who completed the experimental treatment reported treatment gains. The effects of the experimental treatment were large and may have been reduced because some patients in the control group will have probably tried to recognise prodromal symptoms of relapse on their own. ${ }^{10}$

The experimental treatment does not require a skilled therapist, but attention to detail is essential to identify accurately the nature and timing of prodromal symptoms of manic relapse. Cost effectiveness studies of the identification of manic prodromes followed by early treatment are required before the intervention is systematically introduced into the NHS.

We thank Brian Faragher for statistical advice and our colleagues in South Manchester, Guild (Preston), Trafford, and Stockport NHS Trusts who referred patients.

Contributors: NT and RM designed the protocol, initiated and coordinated the study, successfully applied for funding, interpreted the data, and wrote the paper. NT and RM are guarantors of the study. NT and AP designed the experimental treatment and NT supervised AP in delivering the experimental treatment. AP, EMcC, and RM analysed the data. AP, KL, and $\mathrm{EMcC}$ recruited patients into the trial and executed the trial.

Funding: This study was funded by a project grant awarded

by the North West Regional Health Authority.

Competing interests: None declared.

1 American Psychiatric Association. Diagnostic and statistical manual of mental disorders, third edition revised. Washington, DC: APA, 1987.

2 Coryell W, Keller M, Endicott J, Andreasen N, Clayton P, Hirschfeld R. Bipolar II illness: course and outcome over a five year period. Psychol Med 1989;19:129-41

3 Harrow M, Goldberg JF, Grossman LS, Meltzer HY. Outcome in manic disorders. A naturalistic follow-up study. Arch Gen Psychiatry 1990;47:66571.

4 Tohen M, Waternaux GM, Tsuang MT. Outcome in mania: a 4 year prospective follow-up of 75 patients utilising survival analysis. Arch Gen Psychiatry 1990:47:1106-11.

5 Keller MB, Lavori PW, Coryell W, Endicott J, Mueller TI. Bipolar I: a five year prospective follow up. J Nerv Ment Dis 1993;181:238-45.
6 Gitlin MJ, Swendsen J, Heller TL, Hammen C. Relapse and impairment in bipolar disorder. Am J Psychiatry 1995; 152:1635-40.

7 Keck PE, McElroy SL, Strakowski SM, West SA, Sax KW, Hawkins JM, et al. 12 month outcome of patients with bipolar disorder following hospitalisation for a manic or mixed episode. Am J Psychiatry 1998;155: 646-52.

8 Molnar G, Feeney M, Fava G. The duration and symptoms of bipolar prodromes. Am J Psychiatry 1988;145:1575-8.

9 Smith J, Tarrier N. Prodromal symptoms in manic depressive psychosis Soc Psychiatry Psychiatric Epidemiol 1992;27:245-8.

10 Lam D, Wong G. Prodromes, coping strategies, insight and social functioning in bipolar affective disorders. Psychol Med 1997;27:1091-100.

11 Altman ES, Rea MM, Mintz J, Miklowik DJ, Goldstein MJ, Hwang S. Prodromal symptoms and signs of bipolar relapse: a report based on prospectively collected data. Psychiatr Res 1992;41:1-8

12 Keller MB, Lavori PW, Kane JM, Gelenberg AJ, Rosenbaum JF, Walzer EA, et al. Subsyndromal symptoms in bipolar disorder: a comparison of standard and low serum levels of lithium. Arch Gen Psychiatr 1982;49:371-6.

13 Spitzer RL, Williams JBW, Gibbon M, First MB. Structured clinical interview for DSM-III-R, patient edition. Washington, DC: APA, 1990.

14 Pocock ST. Clinical trials: a practical guide. Chichester: Wiley, 1983

15 Kessing LV. Recurrence in affective disorder. II. Effect of age and gender. Br J Psychiatry 1998;172:29-34.

16 Maj M, Pirozzi R, Magliano L, Bartoli L. Long-term outcome of lithium prophylaxis in bipolar disorder: a 5-year prospective study of 402 patients at a lithium clinic. Am J Psychiatry 1998;155:30-6.

17 Miklowitz D, Goldstein M, Nuechterlein K, Snyder M, Mintz J. Family factors and the course of bipolar affective disorders. Arch Gen Psychiatry 1988;45:225-30.

18 Perry A, Tarrier N, Morriss R. Identification of prodromal signs and symptoms and early intervention in manic depressive psychosis patients: a case example. Behav Cognit Psychother 1995;23:399-409.

19 Young MA, Grabler P. Rapidity of symptom onset in depression. Psychiat Res 1985;16:309-15.

20 Hurry J, Sturt E, Bebbington P, Tennant C. Socio-demographic associations with social disablement in a community sample. Soc Psychiatry 1983;18:113-21.

21 World Health Organisation. Anatomical therapeutic chemical (ATC) classification index including defined daily doses (DDDs) per plan substances. Oslo: WHO Collaborating Centre for Drug Statistics and Methodology, 1994.

22 Hlastala SA, Frank E, Mallinger AG, Thase ME, Ritenour AM, Kupfer DJ Bipolar depression: an underestimated treatment challenge. Depression Anxiety 1997;5:73-83.

23 Gater RA, Dean C, Morris J. The contribution of childbearing to the sex difference in first admission rates for affective psychosis. Psychol Med $1989 \cdot 19 \cdot 719-24$

24 Tarrier N, Yusupoff L, Kinney C, McCarthy E, Gledhill A, Haddock G, et al. Randomised controlled trial of intensive cognitive behaviour therapy for patients with chronic schizophrenia. BMJ 1998;317:303-7.

(Accepted 28 October 1998)

\section{Association between maternal anxiety in pregnancy and increased uterine artery resistance index: cohort based study}

Jerónima M A Teixeira, Nicholas M Fisk, Vivette Glover

\begin{abstract}
Objective To investigate whether maternal anxiety in the third trimester is associated with an increased uterine artery resistance index.

Design Cohort based study.

Subjects 100 pregnant women, with a mean gestation of 32 weeks.

Outcome measures Self rating Spielberger questionnaire for state anxiety and trait anxiety, and uterine blood flow waveform patterns as assessed by colour Doppler ultrasound.

Results A significant association was found between uterine artery resistance index and scores for both Spielberger state anxiety and trait anxiety $\left(r_{\mathrm{s}}=0.31\right.$, $\mathrm{P}<0.002$ and $0.28 \mathrm{P}<0.005$ respectively). Women with state anxiety scores $>40(n=15)$ had a higher mean uterine resistance index than those with scores
\end{abstract}

$\leqslant 40$ (mean difference with mean resistance index $24 \%, 95 \%$ confidence interval $12 \%$ to $38 \%$; $\mathrm{P}<0.0001)$. Similarly, women with trait anxiety scores $>40(n=32)$ had a higher mean resistance index than those with scores $\leqslant 40$, although to a lesser extent. The presence of notches in the waveform pattern produced by uterine artery blood flow was found in 4/15 (27\%) women with high state anxiety scores compared with $4 / 85(5 \%)$ with low anxiety scores $(\mathrm{P}<0.02)$

Conclusions This study shows an association between maternal anxiety in pregnancy and increased uterine artery resistance index. It suggests a mechanism by which the psychological state of the mother may affect fetal development, and may explain epidemiological associations between maternal anxiety and low birth weight. The influence of maternal anxiety may be one mechanism by which
Centre for Fetal Care, Division of Paediatrics,

Obstetrics and

Gynaecology,

Queen Charlotte's and Chelsea

Hospital, London W6 $0 \mathrm{XG}$

Jerónima M A

Teixeira,

research fellow

Nicholas M Fisk, professor of obsetrics and gynaecology

Vivette Glover,

reader in perinatal psychobiology

Correspondence to: Dr Glover vglover@rpms.ac.uk

BMJ 1999;318:153-7 